\title{
Dual-Factor Model of Mental Health: Surpass the Traditional Mental Health Model
}

\author{
Xinqiang Wang, Dajun Zhang*, Jinliang Wang \\ Research Center of Mental Health Education, Southwest University, Chongqing, China. \\ Email: zhangdj@swu.edu.cn \\ Received August 13 ${ }^{\text {th }}, 2011$; revised September $17^{\text {th }}, 2011$; accepted October $22^{\text {nd }}, 2011$.
}

\begin{abstract}
Aiming at the limitations of traditional mental health model, the dual-factor model of mental health (DFM) was proposed as a new idea under the background of positive psychology trend. According to the DFM, mental health is a complete state; subjective well-being should be included into the mental health evaluation system as a positive indictor; in terms of prevention and intervention, the DFM asserted that the decrease of symptoms is only the first step of intervention, and the improvement of subjective well-being should be followed, in order to achieve the complete mental health states and reduce the recurrence of illness. Finally, this paper put forward evaluation on DFM and its future research directions.
\end{abstract}

Keywords: Dual-Factor Model of Mental Health, Subjective Well-Being, Psychopathology, Psychological Suzhi

\section{Introduction}

There has been the fourth edition of the Diagnostic and Statistical Manual of Mental Disorders (DSM), DSM-IV, issued by American Psychiatric Association since all countries are paying increasing attentions to human being's mental health. The DSM-IV includes the diagnostic standards and therapeutic plans for more than 340 kinds of mental or psychopathologic illness, but it does not actually relieve psychological patients from the pain. Instead, the number of psychological patients across the world is doubled and redoubled (Ren, 2006). Therefore, we should reflect the traditional mental health model and strive to find a new and scientific mental health model with high effectiveness and efficiency. The Dual-Factor Model of Mental Health (DFM) is a new mental health concept and methodology that is made based on positive psychological concepts and relevant empirical evidences to solve the deficiency in traditional mental health models.

At present, although many scholars have proposed DFM, and have conducted the relevant empirical research, systematic illustration is not available. Therefore, the present article tries to, based on previous work on DFM, systematically illustrates the background, basic opinions and the relevant empirical research of DFM; briefly introduces the contributions of DFM; and focuses on criticizing the deficiencies and further research directions of DFM.

\section{Background to Make the Dual-Factor Model of Mental Health}

\section{Deficiency in Traditional Mental Health Models}

It is too dependent on one-dimensional and negative indicators of diagnosis (i.e., psychopathology). Traditional mental health diagnosis generally uses negative psychopathology (PTH) indicator and takes the DSM as standards for psychological diagnosis. As a widely used diagnostic standard, DSM is playing a positive role in diagnosing and treating mental disorder. However, this diagnostic tool just defines whether there is mental disorder or not in respect of mental health and relates it with negative results. Mental health is thus deemed as an in- ferred by-product of "no mental illness" (Suldo, \& Shaffer, 2008). Mental health and mental illness are deemed as two opposite poles of a continuum (Greenspoon, \& Saklofske, 2001). The research into mental health is restricted in the psychopathology and focuses on mental disorder (Keyes, 2007; Doll, 2008) and neglects the patient's capacity of self-restoration and self-upgrade (Carr, 2008).

There are risks of overestimation or underestimation in diagnosing individual's mental health. It is unsure whether the mental health diagnosis system based on DSM is reliable and effective (Davies, \& Bhugra, 2008). According to such traditional one-dimensional and negative indicators of diagnosis (i.e., psychopathology), if the disorder does not meet certain standards, the individual will be classified as subclinical. The mental health of those subclinical individuals may be overestimated to a large extent and their future development may be in risk. However, they cannot be discriminated in psychopathologic tests, so they will not be intervened with and prevented (Greenspoon \& Saklofske, 2001; Suldo, \& Shaffer, 2008).

In addition to overestimation of subclinical individuals' mental health, the mental health of individuals who have mental illness may be underestimated. They may be restored to mental health step by step without intervention (Greenspoon \& Saklofske, 2001; Keyes, 2007; Suldo, \& Shaffer, 2008), or obtain mental health by increasing individual's positive forces (Dunn, \& Dougherty, 2005).

There are partially effective intervention, ineffective intervention and relapse in respect of the effect of intervention. The concern of traditional mental health models is whether there is mental illness and their main purpose is to relieve symptoms (Keyes, \& Lopez, 2002; Seligman, 2008). Findings through etiology and improvements in diagnostic tools have made much diagnosis clearer, and many effective talk therapies and selective serotonin reuptake inhibitors (SSRI) reduce and relieve the symptoms. However, such therapy may only have partial or transient effects, or in respect of some mental illness, there are even ineffective interventions or relapse. Let's take depression for example. Many patients' depressed symptoms, after being treated with SSRI, are just relieved partially or transiently and there is no effect for one third of the patients who take medica- 
tion (O’Reardon, Brunswick, \& Amsterdam, 2000). Moreover, according to many therapies, the symptom relief can only last a short period, and $60 \%$ to $70 \%$ of unipolar major depression patients have suffered relapse in 6 months (Ramana, et al., 1995).

\section{Some Positive Indicators (i.e. Subject Well-Being, SWB) Concerned More and More People}

Traditional mental health models are too dependent on PTH indicator, which is unhelpful for correctly understanding and assessing metal health (Greenspoon, \& Saklofske, 2001). Researchers begin to question the effects. Jahoda began to question the concept that "to achieve mental health is to eliminate mental illness" as early as 1958 . He believed that "the absence of disease may constitute a necessary, but not sufficient, criterion for mental health” (p. 15) (Jahoda, 1958). Cowen (1991) ever advocated human beings to intensify the research into optimal development, and he believed that "wellness is something more than/other than the absence of disease, that is, it is defined by the 'extent of presence' of positive marker characteristics” (p. 154).

After primary prevention and the campaign for health promotion, the positive psychology movement emerged and people further corrected the normal form mainly targeted for morbid psychology. They believed that it was necessary to add such positive indicators as SWB into the mental health assessment system in order to identify the individual or group whose mental health was at high risk or re-worsened, which challenged the one-dimensional definition that mental health is that an individual has no PTH symptoms. Diener et al. believed that the absence of disease is not an adequate criterion to describe a person as mentally healthy, particularly not as possessing high or even average levels of SWB (Diener, Lucas, \& Oishi, 2002; Seligman, 2008). They also believed that, even an individual's mental illness have been cured, it cannot maintain or ensure his/ her mental health (Keyes, 2007; Suldo, \& Shaffer, 2008). Therefore, they believed that integration of the positive indicator SWB and the negative PTH indicator in mental health assessment will be helpful to comprehensively understand mental health (Cowen, 1994; Greenspoon, \& Saklofske, 2001; Park, 2004; Snyder et al., 2003; Huebner, Valois, Suldo, et al., 2004; Huebner, Gilman \& Suido, 2007; Suldo \& Shaffer, 2008). The
Dual-Factor Model of Mental Health was gradually established in the aforesaid background.

\section{Basic Concepts of Dual-Factor Model of Mental Health}

The Dual-Factor Model of Mental Health mainly covers two stages which takes emergence of positive psychology as the boundary. The first stage is before the emergence of positive psychology. It is the embryonic stage of the Dual-Factor Model of Mental Health when the concept of this model was preliminarily put forward and the two-dimensional structure, consisting of mental illness and SWB, was verified by measurement among adults and teenagers (Veit, \&Ware, 1983; Wilkinson, \& Walford, 1998). The second stage is from the emergence of positive psychology to the future. Theoretical explanation and relevant empirical research was made around connotation, diagnosis, classification of people, prevention and intervention in respect of mental health (Greenspoon, \& Saklofske, 2001; Keyes, \& Lopez, 2002; Keyes, 2002, 2005, 2007; Suldo, \& Shaffer, 2008; Doll, 2008). Since the model was put forward by different scholars in different periods, different terms with the same meaning appeared. For example, Greenspoon and Saklofske put forward the Dual-Factor Model of Mental Health in 2001 for the first time and named it as "dual-factor system (DFS) of mental health"; Keyes and Lopez named it in 2002 as "Mental Health and Mental Illness: The Complete State Model"; Keyes named it in 2005 as "Complete State Model of Mental Health"; Keyes renamed it in 2007 as "Two Continua Model of Mental Health and Illness"; Suldo and Shaffer, Doll named it in 2008 as "Dual-Factor Model of Mental Health". We have concluded such different terms used by different scholars for this model by referencing existing literatures on the Dual-Factor Model of Mental Health. Please see the following Table 1 for details.

\section{Mental Health Should Be a Complete State}

Traditional mental health models used the one-dimensional perspective and placed the SWB and PTH symptoms on two opposite poles. However, the Dual-Factor Model of Mental Health insists from a more comprehensive perspective that mental health is not the absence of mental illness or the high

Table1.

Terms used for dual-factor model of mental health.

\begin{tabular}{|c|c|c|c|}
\hline \multirow{2}{*}{$\begin{array}{c}\text { Psychopathology (PTH)/ } \\
\text { Mental Illness/ } \\
\text { DSM-III-R 12-month } \\
\text { mental illness diagnosis }\end{array}$} & \multicolumn{3}{|c|}{$\begin{array}{c}\text { Subject Well-Being (SWB)/ } \\
\text { Subjective well-being symptoms } \backslash \text { Mental health diagnosis }\end{array}$} \\
\hline & $\begin{array}{c}\text { Low } \\
\text { Low SWB/Low well-being } \\
\text { symptoms/ } \\
\text { Languishing/ }\end{array}$ & $\begin{array}{c}\text { Moderate } \\
\text { Moderate SWB/ } \\
\text { Moderately mentally } \\
\text { healthy }\end{array}$ & $\begin{array}{c}\text { High } \\
\text { High SWB/High well-being } \\
\text { symptoms/Flourishing/ }\end{array}$ \\
\hline $\begin{array}{c}\text { Low } \\
\text { Low PTH/No } \\
\text { Low Mental Illness/ }\end{array}$ & $\begin{array}{c}\text { Incomplete Mental Health I/ Low } \\
\text { SWB-low PTH/ } \\
\text { Incomplete mental } \\
\text { health/Languishing/ } \\
\text { Pure Languishing/ } \\
\text { Dissatisfied/Vulnerable }\end{array}$ & $\begin{array}{l}\text { Incomplete Mental Health II/ } \\
\text { Moderate mental } \\
\text { health/Incomplete mental } \\
\text { health/ }\end{array}$ & $\begin{array}{c}\text { Complete Mental Health/ } \\
\text { High SWB-low PTH/ } \\
\text { Flourishing: Complete mental } \\
\text { health/Flourishing/Well adjusted/ }\end{array}$ \\
\hline $\begin{array}{c}\text { High } \\
\text { High PTH/Yes } \\
\text { High Mental Illness/ }\end{array}$ & $\begin{array}{l}\text { Complete Mental Illness } \\
\text { Low SWB-high PTH/ Mental } \\
\text { illness and languishing/ } \\
\text { Depressed and Languishing/ } \\
\text { Distressed/Troubled }\end{array}$ & $\begin{array}{c}\text { Incomplete Mental Illness II } \\
\text { Mental illness and } \\
\text { moderately mentally healthy/Incomplete } \\
\text { mental illness/Pure Depression }\end{array}$ & $\begin{array}{c}\text { Incomplete Mental Illness I } \\
\text { High SWB-high PTH/ } \\
\text { Incomplete mental illness/Mental } \\
\text { illness and Flourishing/Externally } \\
\text { maladjusted/Symptomatic but } \\
\text { content/Pure Depression }\end{array}$ \\
\hline
\end{tabular}


SWB, but a complete state that integrates the absence of mental illness and the high SWB (Greenspoon, \& Saklofske, 2001; Keyes, \& Lopez, 2002; Keyes, 2005; Keyes, 2007; Suldo, \& Shaffer, 2008; Doll, 2008). The positive indicator and negative indicator of mental health (i.e. SWB and PTH symptoms) compose a pair of continuums as two independent but correlative structures.

\section{Classifies the Mentally Healthy People}

Traditional mental health diagnosis was to simply define whether there was mental disorder or not or whether it is correlative with negative results. The diagnosis system was absolutes and thus deficient (Davies, \& Bhugra, 2008). However, the Dual-Factor Model of Mental Health takes SWB, the positive indicator, and PTH symptoms, the negative indicator as two indispensable factors for mental health diagnosis and thus generates two mental health states and two mental illness states. In this model, the mental health states include a complete state and an incomplete state and the mental illness states also include a complete state and an incomplete state. It can be used to classify people into different groups based on such states and to forecast the mental health functions of those different groups and the development trend of their mental health according to the above mentioned two indicators (Keyes, \& Lopez, 2002; Suldo, \& Shaffer, 2008). The quartered classification theory and the derived sextupled classification theory have been established up to now.

Quartered classification theory. Greenspoon and Saklofske (2001), Keyes and Lopez (2002) as well as Suldo and Shaffer (2008) et al. classified the people into four groups according to PTH and SWB, i.e. complete mental health, incomplete mental health, incomplete mental illness and complete mental illness.

Completely mentally healthy people have low PTH and high SWB, and Keyes $(2002,2007)$ also called them as "flourishing". Complete mental health is a state that integrates high SWB and no recent PTH and is the optimal wellness of individuals. Therefore, individuals in this group can perform emotional vitality as well as good psychological and social functions. It can be forecasted that they will suffer no mental illness in the near future (12 months) (Keyes, 2007).

Incompletely mentally healthy people have low PTH and low SWB. Suldo and Shaffer (2008) called them as "vulnerable", while Keyes $(2002,2007)$ called them as "languishing”. They were always overestimated by traditional mental health models since their PTH symptoms did not reach the PTH diagnosis standards. They were often excluded from the research and the service (Suldo, \& Shaffer, 2008). However, they may need psychological help in fact since they may become languishing or suffer mental disorder in future development. A longitudinal research made by Lewinsohn et al. (1991) proved such possibility. It was found that the non-depressed participants whose life satisfaction scores were low at the beginning may become depressed two or three years later (compared with those whose life satisfaction scores were high or at the average level).

Incomplete mental illness patients have high PTH and high SWB, and Suldo and Shaffer (2008) also called them "symptomatic but content". Even though they have mental illness, such as depression, they have positive characteristics, such as moderate or high SWB. Therefore, perhaps they do not have the same level of mental disorder even though they are identified as abnormal (Suldo, \& Shaffer, 2008). Researchers forecast that they may easily recover from mental illness due to expansion and formation of positive emotions and positive cognitive judgments of life, which is consistent with Bohart and Tallman's concept that "patients are able to cure themselves" and Hoyt's ideas on new directions of psychotherapy innovation (Keyes, \& Lopez, 2002).

Complete mental illness patients have high PTH and low SWB, and Suldo and Shaffer (2008) called them as "troubled". Complete mental illness is a syndrome that integrates low SWB and recent mental illness, such as depression. Therefore, the adults suffering complete mental illness will not only have the syndrome of depression, but also feel unsatisfied with the life and have poor psychological and social functions.

Greenspoon and Saklofske (2001), Suldo and Shaffer (2008) preliminarily verified the existence and availability of quartered classification theory of Dual-Factor Model of Mental Health among primary school students and junior middle school students respectively by empirical evidence. For example, Suldo and Shaffer (2008) found during typical sampling among middle school students that completely mentally healthy students accounted for $57 \%$, vulnerable (incompletely mentally healthy) students accounted for $13 \%$, symptomatic but content students (incomplete mental illness) accounted for 13\%, and trubled students (complete mental illness) accounted for $17 \%$. This research also indicated that there was significant difference among such four groups in respect of academic outcomes, physical health, and social functioning: completely mentally healthy (low PTH and high SWB) students had better reading skills, school attendance, academic self-perceptions, academicrelated goals, social support from classmates and parents, selfperceived physical health, and fewer social problems than incompletely mentally healthy (low PTH and low SWB) students and those suffering incomplete mental illness (high PTH and high SWB); among the students with clinical PTH syndromes (including complete mental illness and incomplete mental illness), those with higher SWB (i.e. those suffering incomplete mental illness) were more aware of social functions and physical health.

Sextupled classification theory. Keyes put forward the sextupled classification theory based on the quartered classification theory (Keyes, 2002, 2005, 2007). He replaced low/high PTH syndromes (PTH standard) in the quartered classification theory with yes/no, and re-divided high and low mental health (i.e. SWB) in the quartered classification theory into high, moderate and low SWB. Keyes used three terms for this purpose, i.e. flourishing (i.e. high SWB), languishing (i.e. low SWB) and moderately mentally healthy (i.e. moderate SWB). People can thus be re-classified into 6 groups according to the two dimensions: complete mental health, incomplete mental health I, incomplete mental health II, complete mental illness, incomplete mental illness I and incomplete mental illness II.

Keyes found in the research into 3,032 25 - 74 year-old American adults that complete mental health (flourishing) accounted for $17.2 \%$, incomplete mental health I (pure languishing) accounted for $12.1 \%$, incomplete mental health II (moderate mental health) accounted for 56.6\%, complete mental illness (depressed and languishing) accounted for $4.7 \%$, incomplete mental illness I (pure depression) accounted for $0.9 \%$, and incomplete mental illness II (pure depression) accounted for 8.5\% (Keyes, 2002). He also found in following research that there was significant difference among those groups in respect of health awareness, restriction of daily activities, psychosocial functioning, working days, use of health care services etc. Completely mentally healthy adults had the fewest missed days of work, the fewest half-day or greater work cutbacks, the healthiest psychosocial functioning (such as low helplessness, 
clear goals in life, high resilience, and high intimacy), the lowest risk of cardiovascular disease, the lowest number of chronic physical diseases with age, the fewest health limitations of activities of daily living, and lower health care utilization (Keyes, 2007). Therefore, he advocated improving mental health status, maintaining completely mentally healthy (flourishing) and taking it as the supplementary strategy for improving Americans' mental health status so as to prevent Americans from mental illness and cure such illness if any.

\section{Purpose of Psychological Prevention and Intervention}

Previous research showed that individuals' mental disorder in early stage may induce other complications, increase the probability of relapse of mental illness and make the treatment more complicated (Keyes, \& Lopez, 2002). Therefore, the Dual- Factor Model of Mental Health emphasizes positive prevention and advocates to use the aforesaid two-dimensional (PTH and SWB) classification standard to identify which individual need improve the SWB in order to actively prevent mental illness and which individual need intervention, especially to identify incompletely mentally healthy group and those suffering incomplete mental illness, so as to effectively solve the problem that traditional one-dimensional PTH indicator system eliminates incomplete mental health from prevention and intervenetion and to make such prevention and intervention more specific and better targeted (Suldo, \& Shaffer, 2008).

In respect of intervention and treatment, this model no longer makes patients remain incompletely mentally healthy (languishing) and deems disappearance of syndromes as the end of treatment, but holds that incomplete mental health may be the intermediate point for individuals to suffer mental illness or go completely mentally healthy. "Symptom reduction may be only a first step in treatment” (p. 50-51) (Keyes, \& Lopez, 2002). It insists that intervention and treatment should help people overstep the base line of their previous psychological functions and finally achieve complete mental health (see Figure 1). It believes that the enhancement of such positive factors as SWB will improve the effects of intervention and treatment and complete mental health may effectively reduce the probability of relapse. If there is any sign of relapse within several months after a patient receives the treatment, psychological diagnosis may confirm that he/she is an incompletely mentally healthy individual and further treatment is required to make him/her achieve complete mental health.

Koivumaa-Honkanen et al. found in the six-year tracking research on the adult sufferer of mental illness that the most effective intervention method is to not only reduce the PTH syndrome, but also improve the patient's SWB and psychological resources so that the patient can better profit from it (Koivu-

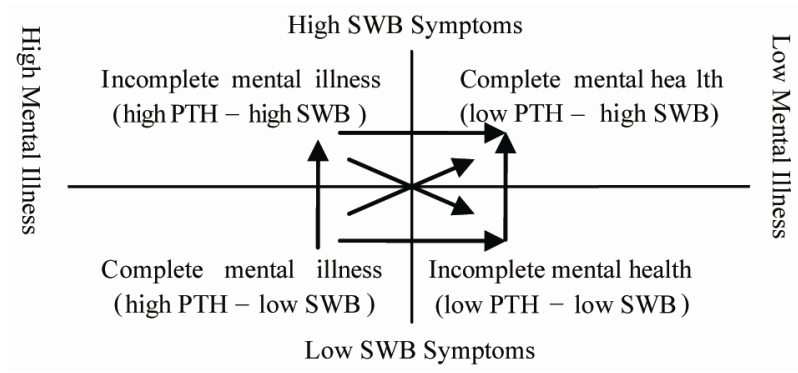

Figure 1.

Making changes beyond baselines. Note: this figure was made with reference to Keyes and Lopez's literatures (2002).
maa-Honkanen, et al., 2008). This has, to a certain extent, described the important role of such positive factors as SWB in intervention and treatment and supported the aforesaid views of the Dual-Factor Model of Mental Health.

\section{Brief Appraisal and Prospect of Dual-Factor Model of Mental Health}

The Dual-Factor Model of Mental Health emphasizes that mental health is a complete state, which is to overcome the clinical deficiencies in traditional mental health PTH. It changes the one-dimensional model (there is/there is no mental illness) and is a self-improvement in the mental health research field. Present empirical research among teenagers and adults has proved the existence of this model and that it can effectively classify people into different groups. This model not only emphasizes the important role of SWB in mental health, but also advocates PTH indicator. It further emphasizes the unsubstitutability and indispensability of the two indicators (Greenspoon, \& Saklofske, 2001; Keyes, 2007; Suldo, \& Shaffer, 2008; Doll, 2008). This also provides theoretical support for positive mental illness prevention and treatment (Seligman, 2008) and positive mental health education (Meng, 2008). That is to say, mental health services must include cultivation of such positive factors as SWB (Weissberg, Kumpfer, \& Seligman, 2003; Weisz, Sandler, Durlak, \& Anton, 2005), and obtaining positive strengths is the necessary precondition for individuals to obtain optimal academic (or working) achievement and optimal physical and mental health (Keyes, 2007; Suldo, \& Shaffer, 2008).

This model can distinguish the complete state from incomplete state of mental illness and mental health and make diagnosis, which will generate more effective prevention and intervention plans and thus improve the standards on relieving PTH syndromes (Keyes \& Lopez, 2002; Suldo \& Shaffer, 2008). School psychologists and health care service providers should consider including SWB scale into individual's routine evaluation (such as psychological survey and physical and psychological examination) in order to better determine an individual's position in the multi-layer service provision model, distinguish incompletely mental illness people from those suffering complete mental illness and provide the maximum-strength intervention for complete mental illness sufferers. We believed that the Dual-Factor Model of Mental Health will cause profound influence to mental health and the whole education and public health sector in the near future.

"New-born things definitely have an ugly appearance", so the Dual-Factor Model of Mental Health also has some deficiencies and requires further research:

First, the connotation of SWB is to be determined. The existence of SWB is the key that distinguishes the Dual-Factor Model of Mental Health from traditional one-dimensional PTH indicator. However, the present psychological circle does not have a fixed definition of SWB and no common understanding has been achieved (Gao \& Zheng, 2009). Some scholars, such as Greenspoon, Saklofske, Suldo and Shaffer, believed that the connotation of SWB should be composed of life satisfaction, positive affect and negative affect in this model, while Keyes and Lopez et al. believed that SWB should include emotional well-being, psychological well-being and social well-being. Therefore, researchers need, on one hand, further "define the well-being, strengthen the research into meaning of well-being and build a more reasonable structure of well-being” (Gao \& Zheng, 2009), and, on the other hand, need repeatedly add 
SWB indicator into empirical research into the dual-factor model and examine continuously to find out the most sensitive SWB indicator and measurement tool.

Second, the forecast function of the Dual-Factor Model of Mental Health is to be further proved. Although some empirical research supports this model in respect of the ideas that "completely mentally healthy people can be free from mental illness", "incomplete mental illness sufferers are more likely to recover by themselves" and "incompletely mentally healthy people may suffer mental disorder in future development”. However, this is far from enough for proving the effective forecast functions of this model, so much experimental verification is required in further research for the forecast functions of this model, such as related longitudinal research.

Third, the guiding effect of Dual-Factor Model of Mental Health for intervention therapy is to be confirmed. Present research has proved that some intervention measures may enhance the SWB (Wang \& Wang, 2008; Meng, 2008). However, what degree of SWB can be deemed as the end of intervention therapy? Is it true that a completely mentally healthy people will not suffer relapse of any mental illness? Such problems need further research and verification.

Fourth, are there any other positive indicators, in addition to SWB, in the Dual-Factor Model of Mental Health? Can positive cognition (such as optimism) and positive personality (such as psychological resilience) beyond positive subjective experiences (Meng, 2008; Doll, 2008) as well as endogenous psychological suzhi (Zhang, Wang, \& Yu, 2011) be included into or be used to replace SWB? Those require further discussion. It should be noted that it also deserves discussion whether the localized indicator in China "psychological suzhi" should be included into or be used to replace SWB so as to better perform the functions of this model. For example, Zhang et al. also put forward in the 1990s the idea consistent with positive psychology and the Dual-Factor Model of Mental Health and started the research that integrated school mental health education and cultivation of students' sound psychological suzhi (Zhang, 2004; Zhang, \& Feng, 2000; Zhang, Wang, \& Yu, 2011). They indicated: the current school mental health education actually inherited traditional mental health education. It only focused on the "adaptability" function of mental health education, but ignored its "development" function; it was only targeted for a few students with mental disorder or illness, but ignored the majority of them; it only emphasized problems in explicit behavior, but ignored the solution of endogenous problems and the cultivation of sound psychological suzhi for students. They insisted "the school mental health education mode, whose precondition is to keep students mentally healthy (symptom), whose basic purpose is to cultivate sound psychological suzhi for students (essence) and whose major task is to guide students to actively adapt to the environment and improve students' positive development, and its new research concepts” (Zhang, 2004). They believed that "generally speaking, the people with sound and high psychological suzhi are unlikely to suffer mental disorder; even though mental disorder appears, they are generally able to make self-adjustment to keep themselves mentally healthy. Contrarily, the people with unsound or low psychological suzhi are likely to suffer mental disorder; they are even unable to make self-adjustment in case of any mental disorder and thus are often suffer mental illness” (Zhang, 2004). It can be easily concluded that the role of high/low psychological suzhi here are extremely similar to that of high/low SWB in the Dual-Factor Model of Mental Health. Therefore, psychological suzhi should be included in the model to develop relationship model between psychological suzhi and mental health in further research (Wang, \& Zhang, 2011). It will be the new research area of mental health research.

\section{Acknowledgements}

This study was supported by the fund of School Social Work Safeguard System for College and Middle School Student's Mental Health (06XSH012), and supported by the fund of Psychological research for contemporary university students' social adaptation(10JHQ003).

\section{References}

Carr. A. (2008). Positive psychology: The Science of Happiness and human Strengths (X. Zheng, Trans.). Beijing: China Light Industry Press.

Cowen, E. L. (1994). The enhancement of psychological wellness: Challenges and opportunities. American Journal of Community Psychology, 22, 149-179. doi:10.1007/BF02506861

Davies, D. \& Bhugra, D. (2008). Models of psychopathology (T. Lin, Trans.). Beijing: Peking University Medical Press.

Diener, E., Lucas, R. E., \& Oishi, S. (2002). Subjective well-being: The science of happiness and life satisfaction. In C. R. Snyder \& S. Lopez (Eds.), Handbook of positive psychology (pp. 463-473). London: Oxford University Press.

Doll, B. (2008). The Dual-Factor Model of Mental Health in Youth. School Psychology Review, 37, 69-73.

Greenspoon, P. J., \& Saklofske, D. H. (2001). Toward an integration of subjective well-being and psychopathology. Social Indicators Research, 54, 81-108. doi:10.1023/A:1007219227883

Dunn D. S., \& Dougherty S. B. (2005). Prospects for a positive psychology of rehabilitation. Rehabilition Psychology. 50, 305-311. doi:10.1037/0090-5550.50.3.305

Gao, L., \& Zheng, X. (2009). The Limitations and Further Directions of Western Well-being Researches. Journal of Dialectics of Nature, 31, 84-88.

Huebner, E. S., Gilman, R., \& Suido, S. M. (2007). Assessing perceived quality of life in children and youth. In S. R. Smith \& L. Handler (Eds.), Clinical assessment of children and adolescents: A practitioner's guide (pp. 347-363). Mahwah, NJ: Erlbaum.

Huebner, E. S., Valois, R. F., Suldo, S. M., Smith, L. C., McKnight, C. G., Seligson, J. L., \& Zullig, K. J. (2004). Perceived Quality of Life: A Neglected Component of Adolescent Health Assessment and Intervention. Journal of Adolescent Health, 34, 270-278.

Jahoda, M. (1958).Current concepts of positive mental health. New York: Basic Books. doi:10.1037/11258-000

Keyes, C. L. M. (2002). The mental health continuum: From languishing to flourishing in life. Journal of Health and Social Behavior, 43, 207-222. doi: $10.2307 / 3090197$

Keyes, C. L. M. (2005). Mental illness and/or mental health? Investigating axioms of the complete state model of health. Journal of Consulting and Clinical Psychology, 73, 539-548. doi:10.1037/0022-006X.73.3.539

Keyes, C. L. M. (2007). Promoting and Protecting Mental Health as Flourishing: A Complementary Strategy for Improving National Mental Health. American Psychologist, 62, 95-108. doi:10.1037/0003-066X.62.2.95

Keyes, C. L. M., \& Lopez, S. J. (2002). Toward a science of mental health: Positive directions in diagnosis and interventions. In C. R. Snyder \& S. J. Lopez (Eds.), Handbook of positive psychology (pp. 45-59). New York: Oxford University Press.

Koivumaa-Honkanen, H., Tuovinen, T. K., Honkalampi, K., Hintikka, R. A. J., Haatainen, K., Viinama“ki, H. (2008). Mental health and well-being in a 6-year follow-up of patients with depression-Assessments of patients and clinicians. Social Psychiatry and Psychiatric Epidemiology, 43, 688-696. doi:10.1007/s00127-008-0353-X

Lewinsohn, P., Redner,J., \& Seeley,J. (1991). The relationship between life satisfaction and psychosocial variables: New perspectives, In F. Strack, M. Argyle and N. Schwartz (eds.), Subjective Well-Being (pp. 
141-169). New York: Plenum Press.

Meng, W. J. (2008). Positive mental health education. Beijing: China Light Industry Press.

O’Reardon, J. P., Brunswick, D. J., \& Amsterdam, J. D. (2000). Treatment-resistant depression in the age of serotonin: Evolving strategies. Current Opinion in psychiatry, 13, 93-98. doi:10.1097/00001504-200001000-00016

Park, N. (2004). The role of subjective well-being in positive youth development. Annals of the American Academy of Political \& Social Science, 591, 25-39. doi:10.1177/0002716203260078

Ramana, R., Paykel, E. S., Cooper, z., Hayhurst, H., Saxty, M., \& Surtees, P. G. (1995). Remission and relapse in major depression: A two year prospective follow-up study. Psychological Medicine, 25, 11611170. doi:10.1017/S0033291700033134

Ren, J. (2006). Positive psychology. Shanghai: Shanghai Education Publishing House.

Seligman, M. E. P. (2008). Positive health. Applied Psychology: An International Review, 57, 3-18. doi:10.1111/j.1464-0597.2008.00351.x

Snyder, C. R., Lopez, S. J., Edwards, L. M., Pedrotti, J. T., Prosser, E. C, Walton, S. L., et al. (2003). Measuring and labeling the positive and the negative. In S. J. Lopez and C. R. Snyder (Eds.), Positive psychological assessment: A handbook of models and measures, (pp. 21-39). Washington, DC: American Psychological Association. doi:10.1037/10612-002

Suldo, S. M., \& Shaffer, E. J. (2008). Looking beyond psychopathology: The dual-factor model of mental health in youth. School Psychology Review, 37, 52-68.

Veit, C. T., and Ware, J. E. (1983). The structure of psychological distress and well-being in general populations. Journal of consulting and clinical psychology, 51, 730-742. doi:10.1037/0022-006X.51.5.730

Wang, Y., \& Wang, Y. (2008). A Review of Intervention Studies on Increasing Subjective Well-Being. Psychological science, 31, 1441-1442.

Wang X. Q., Zhang D. J. (2011). The relationship model between psychological suzhi and mental. Abstract Book of the 9th Biennial Conference of the Asian Association of Social Psychology, Yunnan Normal University, 15-16

Wilkinson, R. B., \& Walford, W. A. (1998). The measurement of adolescent psychological health: One or two dimensions? Journal of Youth and Adolescence, 27, 443-455. doi:10.1023/A:1022848001938

Weissberg, R. P., Kumpfer, K. L., \& Seligman, M. E. P. (2003). Prevention that works for children and youth: An introduction. American Psychologist, 58, 425-432. doi:10.1037/0003-066X.58.6-7.425

Weisz, J. R., Sandler, I. N., Durlak, J. A., \& Anton, B. S. (2005). Promoting and protecting youth mental health through evidence-based prevention and treatment. American Psychologist, 60, 628-648. doi:10.1037/0003-066X.60.6.628

Zhang, D. J. (2004). On school psychological suzhi education. Chongqing: Southwest China Normal University Press.

Zhang, D. J., Feng, Z. Z. (2000). A study on the development of the middle school students' mental quality in China. International Journal of psychology, 35, 304-304

Zhang, D. J., Wang, J. L., \& Yu, L. (2011).Introduction. In Zhang, D.J., J. L. Wang and L. Yu (Eds.), Methods and Implementary Strategies on Cultivating Students's Psychological Suzhi. New York: Nova Science Publishers. 